Original Research Paper

\title{
Effect Administration of Omega-3, Omega-6 and Synthetic Cholesterol on Reproductive Characteristic of Male Quail (Coturnix coturnix japonica)
}

\author{
${ }^{1}$ Abyadul Fitriyah, ${ }^{2}$ Supriyono and ${ }^{2}$ Isyaturriyadhah \\ ${ }^{1}$ Faculty of Animal Sciences, The University of Nahdlatul Wathan Mataram, Mataram, Indonesia \\ ${ }^{2}$ Faculty of Agriculture, The University of Muara Bungo, Jambi, Indonesia
}

Article history

Received: 12-09-2018

Revised: $15-10-2018$

Accepted: 03-11-2018

Corresponding Author: Abyadul Fitriyah, Faculty of Animal Sciences, The University of Nahdlatul Wathan Mataram, Jl. Kaktus No. 1-3Mataram, Indonesia Email: fitry_amin@yahoo.com

\begin{abstract}
The bird is one of the most important sources of animal protein for people and smallholders in developing countries. However, it is also important to look at their reproductive activity to maintain a sustainable population. Omega-3, omega-6 fatty acid and synthetic cholesterol may improve reproductive characteristics in animals including quail. Several treatments can be used to improve the quality of reproduction of the quail. The research was conducted to know the effect of the use of omega-3, omega- 6 fatty acid and synthetic cholesterol on sperm quality, testosterone level, the testes and the uropygium size of male quails (Coturnix coturnix japonica). This research used 175 male quails at 6-w old. These divided into seven feed treatment groups. These are; R-0 (control), R-1 (0.163 mg omega-3/100g body weight (BW), R-2 (0.362 mg omega-3/100g BW), R-3 (0.163 mg omega-6/100g BW), R-4 (0.326 mg omega-6/100g BW), R-5 (20 mg cholesterol/100g BW) and R-6 (40 mg cholesterol/100g BW). The treatments were given orally for three different periods, within ten days. The data on testes size, uropygium sizes, and the testosterone level were analyzed statistically. The sperm quality data (sperm motility, sperm morphology, sperm viability, and sperm concentration) were analyzed with the Duncan Multiple Range Test (DMRT). The usage of omega-3, omega-6 fatty acid with a double dose $(0.326 \mathrm{mg})$ showed the best response, which shows a significant increase of the testes weight $(2.64 \mathrm{~g})$, testes circumference $(94.70 \mathrm{~cm})$, testes volume $(2.00 \mathrm{ml})$ and uropygium weight $(2.75 \mathrm{~g})$. Also, there was a significant increase in the level of testosterone $(4.92 \mathrm{ng} / \mathrm{ml})$. The use of double dose of $(0.326 \mathrm{mg})$ omega- 3 and omega- 6 fatty acid or $0.163 \mathrm{mg}$ omega-3 and omega- 6 gave a good quality of sperm, including improvements in sperm motility $(78.30 \%$ and $78.30 \%)$, sperm viability $(73.19 \%$ and $86.06 \%)$ and sperm concentration $(250.00 \times 10 \% \mathrm{ml}$ and $\left.255.30 \times 10^{9} / \mathrm{ml}\right)$.
\end{abstract}

Keywords: Omega-3, Omega-6, Synthetic Cholesterol, Reproductive

\section{Introduction}

Poultry refers to all birds of economic value to humans; examples include chickens, pigeon, duck, pheasant, quail and guinea fowl. Therefore, efforts need to be made to maintain and enhance the quail population, among others, through breeding with their male counterpart to increase their productivity.

The highest population of quails is caused by the ease of breeding. Through breeding, there is an increase in the productivity of the male quail. Productivity can be measured through a reproductive performance by detecting the levels of testosterone hormone, testes size, uropygium size, and spermatogenesis. All these things greatly affect the sexual organs of the female quail.

The fertility of poultry depends on the success of some critical steps of spermatogenesis, extragonadal maturation, survival, and function of sperm in the oviduct. The function of testosterone is on sexual development, which acts in the process of spermatogenesis, extending the viability of spermatozoa in the epididymis, affecting reproductive development and maintaining the development of secondary sexual 
organs in males (Dumpala et al., 2006). To improve the quality of spermatozoa in an animal, there is a need for essential fatty acids (Wathes et al., 2007) and cholesterol (Fitriyah, 2010) which serves as a precursor of testosterone. The sources of essential fatty acids are feed ingredients that contain omega- 3 and omega- 6 .

In male quails, fatty acids and cholesterol are found in high concentration in the reproductive organs.

\section{Materials and Methods}

\section{Experimental Design}

This research used 175 6-w old male quails, with 95 to $148 \mathrm{~g}$ maintained for $12 \mathrm{w}$ and divided randomly into seven feed treatment groups of fatty acid and synthetic cholesterol. The dose used in this study was based on the recommendation of the World Health Organization (WHO) for livestock and humans (Anonymous, 2014a; 2014b; 2014c; 2014d). This study used doses for cattle that can represent livestock including poultry, with calculations as follows: for cattle $=400 \mathrm{~kg}$ body weight (BW) require $650 \mathrm{mg} / \mathrm{kg} \mathrm{BW} /$ day of omega-3 and omega- 6 fatty acids and require $200-300 \mathrm{mg} / \mathrm{kg} \mathrm{BW} /$ day of cholesterol. Determination of the dose conversion to quail $(100 \mathrm{~g})=0.163 \mathrm{mg}$ of omega fatty acids and $20 \mathrm{mg}$ of cholesterol per day. So the dose for each treatment group in this study are: R-0 (control), R-1 (0.163 mg omega-3/100g BW), R-2 (0.362 mg omega-3/100g BW), R-3 (0.163 mg omega-6/100g BW), R-4 (0.326 mg omega-6/100g BW), R-5 (20 mg cholesterol/100g BW) and R-6 (40 mg cholesterol $/ 100 \mathrm{~g} \mathrm{BW})$. The treatments were given to the quail orally. Omega-3, omega- 6 and cholesterol used are: Omega- 3 = eicosapentaenoic acid; omega- $6=5,8,11,14$ eicosatetraenoic acid and synthesis cholesterol $=$ cholesterol NF.

\section{Animals and their Management}

The male quails were given feed with the same composition of crude protein $(20.51 \%)$, fat $(4.46 \%)$, crude fiber $(4.38 \%)$, calcium $(1.54 \%)$, phosphor $(0.77 \%)$ and metabolism energy $(2602.01 \mathrm{Kcal} / \mathrm{kg})$. The quality of feed material was analyzed for proximate ration (corn, rice bran, soya bean meal, meat bone meal, $\mathrm{CaCO}_{3}, \mathrm{DL}-$ methionine, L-lysine, $\mathrm{NaCl}$, and premix).
The variables are sperm quality (motility, morphology, viability, and concentration), testosterone level, testes size (weight, length, circumference, and volume) and uropygium size (weight and circumference).

Feed materials used in the study are presented in Table 1. Feeding was given at 06:00 AM and 04:00 $\mathrm{PM}$, with as much as $20 \mathrm{~g} /$ day. Given drinking water ad libitum.

\section{Blood Sampling}

Blood samples were obtained as much as three times during the study, e.g., at the beginning of the study, midstudy and the end of the study. Blood samples were taken from the jugular venous of the quail in treatment groups (R-0, R-1, R-2, R-3, R-4, R5, and R-6). The analysis of blood includes the level of testosterone, cholesterol, HDL, and LDL.

\section{Semen Collection}

Semen was collected twice a week from each male. Suspension of spermatozoa used for the analysis. Spermatozoa were obtained from vast difference and put into a petri dish containing $1.0 \mathrm{ml}$ of physiological $\mathrm{NaCl}$ $(\mathrm{NaCl} 0.9 \%)$ at a temperature $40^{\circ} \mathrm{C}$, then cut into small pieces using scissors and stirred until smooth. The analysis of spermatozoa includes sperm motility, sperm morphology, sperm viability and sperm concentration (Nalbandov, 1964; Sorensen, 1979).

\section{The methodology used in the Research}

\section{Cholesterol and Testosterone Level}

Total cholesterol was measured by the CHOD-PAP method (Cholesterol Oxidase Phenol Amino Phenazon) (Sudargo et al., 2017).

The concentration of hormones was measured by the Radio Immuno Assay solid phase technique (RIA) method (Brind et al., 1996), using KIT (Diagnostic Product Corporation/DPC, Los Angeles, CA), by blood sampling, using $1 \mathrm{~mL}$ syringe and placed on Eppendorf tube, left overnight, then centrifuged for $5000 \mathrm{rpm}$, for a period $10 \mathrm{~min}$ and a clear liquid was observed. This was analyzed by RIA method (Radio Immuno Assay).

Table 1: The composition of diets used during the research (data were analyzed of each ingredient in 2015)

\begin{tabular}{|c|c|c|c|c|c|c|c|}
\hline Ingredients & Composition $(\%)$ & Crude Protein (\%) & Calcium (\%) & Phosphor (\%) & Crude Fiber (\%) & Fat $(\%)$ & EM (Kcal/kg) \\
\hline Meat Bone Meal & 5.50 & 3.65 & 0.61 & 0.31 & 0.16 & 0.61 & 180.86 \\
\hline Soya Bean Meal & 18.0 & 9.57 & 0.17 & 0.19 & 1.52 & 0.26 & 494.63 \\
\hline Corn & 56.0 & 5.64 & 0.11 & 0.07 & 1.18 & 2.05 & 1622.02 \\
\hline Rice Bran & 13.0 & 1.65 & 0.11 & 0.20 & 1.52 & 1.54 & 304.50 \\
\hline $\mathrm{CaC} 03$ & 6.00 & - & 0.54 & - & - & - & - \\
\hline L-Lysine & 0.35 & - & - & - & - & - & - \\
\hline DL-Methionine & 0.30 & - & - & - & - & - & - \\
\hline Premix & 0.63 & - & - & - & - & - & - \\
\hline $\mathrm{NaCl}$ & 0.22 & _ & _ & - & - & - & - \\
\hline Total & 100.00 & 20.51 & 1.54 & 0.77 & 4.38 & 4.46 & 2602.01 \\
\hline
\end{tabular}




\section{Testes and Uropygium Size of Quail}

The measurement of length, circumference, testes and uropygium weight of male quail: The testes weight (left and right) and uropygium weight were measured and weighed. The length and circumference of testes and uropygium were measured using calipers. The testes volume was measured by inserting testes into a measuring cup containing physiological $\mathrm{NaCl}$, the increase in volume that occurs is assumed to be testis volume.

\section{Histological Profile of the Testical of Quail}

To determine the differences of testes of male quail, at the end of the study, testicles from each treatment (three male quails) were taken, measured and weighed. The testes were made testicular histological microscope slides preparations. Testes were fixed in Bouin's solution and embedded in paraffin. Sections were stained by hematoxylin-eosin.

\section{Sperm Quality}

The analysis of spermatozoa included: (a) Sperm Motility: Sperm suspension was dripped over a glass object and examined under a microscope with a magnification of 100 times. The movements of mass and the movements of individual sperm could be seen; its motility was measured by observing 100 spermatozoa in the field of view. (b) Sperm Morphology: Morphological examination was observed in the use of $3 \%$ eosin staining. The emphasis of the examination was on normal and abnormal form of 100 spermatozoa and the results were expressed as a percentage. (c) Sperm Viability: Sperm variability estimations were performed utilizing a drop of sperm which was put on a glass object and then given one drop of Essen and made air-dry. Observations were made under a microscope with 400 times magnification of 100 spermatozoa. Live spermatozoa were clear color, while the dead were of strong color. The results were expressed in percentage. (d) Sperm concentration: The spermatozoa concentration was measured with a haemocytometer (BobadillaMendez et al., 2016; Chelmonska et al., 2008; Chełmońska et al., 2006): Spermatozoa of pipette erythrocyte suspension was homogenized with methylene blue, dropped into the Neubauer chamber count and observed under the microscope with a magnification of 400 times in five large boxes. The concentration of spermatozoa counted in 5 boxes $(4$ boxes at one end and the middle box) and the numbers are expressed in units X.10 $/ \mathrm{ml}$.

\section{Statistical Analysis}

The data from observations of output from different testes size, uropygium size and testosterone level were analyzed descriptively, by value or by the observed results between the control and the treatment groups. The sperm quality data (sperm motility, sperm morphology, sperm viability, and sperm concentration) were analyzed by Duncan Multiple Range Test (DMRT) (Steel and Torrie, 1980).

\section{Results}

\section{Testosterone Level of Quail after Treatment}

The results of testosterone, cholesterol, HDL and LDL levels of male quail after given omega-3, omega- 6 or synthetic cholesterol are shown in Table 2.

The higher doses of omega-3 and omega-6 (0.362 mg omega/100g BW) increased the level of testosterone, but the higher doses of cholesterol (40 mg cholesterol $/ 100 \mathrm{~g}$ $\mathrm{BW}$ ) decrease the level of testosterone. The doses above are most suitable for poultry, especially quail, but these doses are higher than the WHO recommendation.

\section{Testes and Uropygium Size of Quail}

From the data in Table 3, the quail treated R-2, indicates that the size of the testes is bigger than the other treatments. After that, the size of the bigger testes was indicated in the treatment of R-5, R-4, R-6, R-3, R0 , and R-1 respectively. The testes of quail treated with cholesterol or fatty acids generally have a bigger size than the control subject. The treated quails R-2, R-4 and R-5 show the average weight, average length, average circumference is bigger than the other treatments. The average of testes volume is higher than the other treatment, and this is consistent with the increase in uropygium size.

Table 2: The average of testosterone level, cholesterol, High Density Lipoprotein (HDL) and Low Density Lipoprotein (LDL) of quail

\begin{tabular}{lllll}
\hline Dose $(\mathrm{mg} / 100 \mathrm{~g}$ bw/day) & Testosterone level $(\mathrm{ng} / \mathrm{ml})$ & Cholesterol level $(\mathrm{mg} / \mathrm{dl})$ & HDL level $(\mathrm{mg} / \mathrm{dl})$ & LDL level $(\mathrm{mg} / \mathrm{dl})$ \\
\hline R-0 & 1.68 & 202.50 & 67.10 & 4.24 \\
R-1 & 0.42 & 237.00 & 78.40 & 8.10 \\
R-2 & 4.92 & 174.10 & 46.30 & 18.04 \\
R-3 & 1.39 & 182.60 & 53.70 & 9.54 \\
R-4 & 2.44 & 195.00 & 58.90 & 20,36 \\
R-5 & 220.10 & 71.00 & 6.12 \\
R-6 & 3.08 & 164.20 & 50.00 & 6.48 \\
\hline
\end{tabular}


Abyadul Fitriyah et al. / American Journal of Animal and Veterinary Sciences 2018, 13 (4): 136.142 DOI: 10.3844/ajavsp.2018.136.142

Table 3: The average size of the testes and uropygium of quail

\begin{tabular}{llllllll}
\hline & & \multicolumn{3}{l}{ Testes size } & & \multicolumn{2}{l}{ Uropygium size } \\
& $\begin{array}{l}\text { Body } \\
\text { Treatments }\end{array}$ & $\begin{array}{l}\text { Weight } \\
\text { weight }(\mathrm{g})\end{array}$ & $\begin{array}{l}\text { Length } \\
(\mathrm{g})\end{array}$ & $\begin{array}{l}\text { Circumferences } \\
(\mathrm{cm})\end{array}$ & $\begin{array}{l}\text { Volume } \\
(\mathrm{ml})\end{array}$ & $\begin{array}{l}\text { Weight } \\
(\mathrm{g})\end{array}$ & $\begin{array}{l}\text { Circumferences } \\
(\mathrm{cm})\end{array}$ \\
\hline R-0 & 126.15 & 1.42 & 1.75 & 3.95 & 1.00 & 1.85 & 4.40 \\
R-1 & 122.10 & 1.34 & 1.60 & 3.70 & 0.95 & 2.40 & 3.75 \\
R-2 & 137.55 & 2,64 & 2.00 & 4.70 & 2.00 & 2.75 & 5.20 \\
R-3 & 120.20 & 1.44 & 1.95 & 3.65 & 0.95 & 2.45 & 4.60 \\
R-4 & 128.95 & 1.62 & 2.00 & 3.75 & 1.65 & 2.50 & 5.20 \\
R-5 & 121.15 & 1.66 & 2.00 & 3.88 & 1.50 & 2.58 & 4.48 \\
R-6 & 133.25 & 1.50 & 1.70 & 3.85 & 1.40 & 2.48 & 4.93 \\
\hline
\end{tabular}

Table 4: The effect of treatment on sperm quality of quail (different superscripts in the same row, indicate significant differences $(P<0.01)$ )

\begin{tabular}{|c|c|c|c|c|c|c|c|}
\hline \multirow[b]{2}{*}{ Variable } & \multicolumn{7}{|c|}{ Treatments } \\
\hline & $\mathrm{R}-0$ & $\mathrm{R}-1$ & $\mathrm{R}-2$ & $\mathrm{R}-3$ & $\mathrm{R}-4$ & $\mathrm{R}-5$ & $\mathrm{R}-6$ \\
\hline Sperm Motility (\%) & $71.70^{\mathrm{a}}$ & $73.30^{\mathrm{b}}$ & $78.30^{\mathrm{c}}$ & $78.30^{\mathrm{c}}$ & $78.30^{\mathrm{c}}$ & $76.30^{\mathrm{b}}$ & $73.30^{\mathrm{b}}$ \\
\hline \multicolumn{8}{|l|}{ Sperm Morphology: } \\
\hline Normality $(\%)$ & $55.74^{\mathrm{c}}$ & $61.71^{\mathrm{d}}$ & $23.39^{\mathrm{a}}$ & $28.60^{\mathrm{a}}$ & $42.79^{\mathrm{b}}$ & $56.12^{\mathrm{cd}}$ & $32.39^{\mathrm{a}}$ \\
\hline Abnormality (\%) & $44.36^{\mathrm{b}}$ & $38.39^{\mathrm{a}}$ & $76.70^{\mathrm{d}}$ & $71.49^{\mathrm{d}}$ & $57.31^{\mathrm{c}}$ & $43.98^{\mathrm{a}}$ & $67.70^{\mathrm{c}}$ \\
\hline \multicolumn{8}{|l|}{ Sperm Viability: } \\
\hline Viability (\%) & $54.04^{\mathrm{a}}$ & $73.24^{\mathrm{b}}$ & $73.29^{\mathrm{b}}$ & $79.00 \mathrm{~b}^{\mathrm{c}}$ & $86.06^{\mathrm{c}}$ & $81.43^{\mathrm{c}}$ & $40.94^{\mathrm{a}}$ \\
\hline Unviable (sperm death) (\%) & $45.90^{\mathrm{c}}$ & $26.85^{\mathrm{b}}$ & $26.80^{\mathrm{b}}$ & $20.99^{\mathrm{b}}$ & $13.94^{\mathrm{a}}$ & $18.67^{\mathrm{a}}$ & $59.06^{\mathrm{d}}$ \\
\hline Concentration $(109 / \mathrm{ml})$ & $180.80^{\mathrm{a}}$ & $244.80^{\mathrm{b}}$ & $250.00^{\mathrm{c}}$ & $238.20^{\mathrm{b}}$ & $255.30^{\mathrm{c}}$ & $178.43^{\mathrm{a}}$ & $170.33^{\circ}$ \\
\hline
\end{tabular}

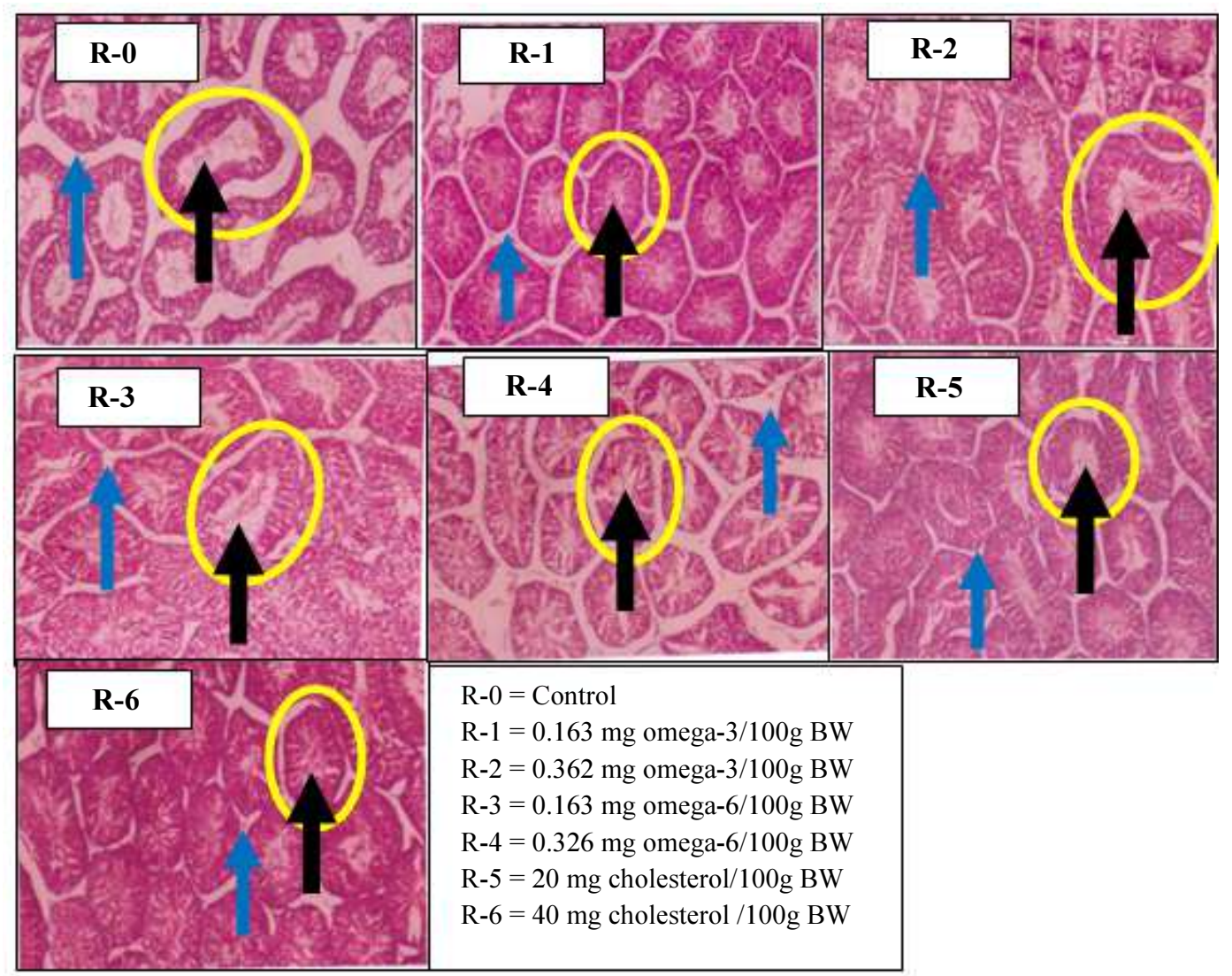

Fig. 1: Comparison of seminiferous tubule of quail testes after being given omega-3, omega- 6 and synthetic cholesterol (400 times magnification). The yellow circle and black arrow $=$ seminiferous tubules of testes. The blue arrow $=$ the distance between seminiferous tubules 


\section{Histological Appearance of Testical of Quails}

The results of the testicular measurements (Table 3) and the histologic conditions are microscopically (Fig.1), indicate that there is a morphological difference between the testes of the quail in the treatment groups (R-1, R-2, $\mathrm{R}-3, \mathrm{R}-4, \mathrm{R}-5$, and R-6) and the control group (R-0).

In Fig. 1, tubules of R-0 (control) is normal morphology with contained spermatogonia (sg) at the periphery of seminiferous tubules, spermatocytes (sp), round spermatids (Rs) and elongating spermatid (Es) soon to be released into the tubule lumen but the distance between the tubules varies or is not compact. Tubules with treatment R-1, R-5, and R-6 indicate normal morphology (contained sq, sp, Rs and Es), the seminiferous tubules were bonded together with normal spermatogenic cell conditions and complete spermatogenesis and they contained collagen fibers, fibroblasts, and groups of Leydig cells. Tubules with treatment R-2 and R-4 indicate normal morphology (contained sq, sp, Rs and Es), these cells were large and contained nucleoli. Tubules with treatment R-4 are not much different from R-0 (control).

\section{Sperm Quality of Quail after Treatment}

The results are listed in Table 4. It appears that when compared with controls to give the real effect, there is significant $(\mathrm{P}<0.01)$ increase in the sperm motility, the sperm viability, and the sperm concentration. Treatment with omega-3 did not significantly improve the sperm motility, but significantly $(\mathrm{P}<0.01)$ increased the sperm viability and the concentration of spermatozoa. The dose of $6 \%$ omega-3 significantly $(\mathrm{P}<0.01)$ increased sperm motility and concentration compared to the dose of $3 \%$.

The addition of omega- 6 treatment significantly $(P<0.01)$ increased sperm motility, sperm viability, and sperm concentration. The dose of $6 \%$ omega- 6 did not significantly improve sperm motility, but significantly $(P<0.01)$ increased sperm normality and lowered the sperm unviable (sperm death) than the dose of $3 \%$.

\section{Discussion}

There have been several reports of reproduction performance in the vital organs of poultry and birds including quail (Bhanja and Verma, 2001) which depend on the content of the feed material e.g. crude protein, fat, crude fiber, calcium, phosphor, energy metabolism and supplements like vitamins (Ipek et al., 2007).

Omega- 3 or omega- 6 can improve the sperm quality of quail (Fitriyah, 2010; Iriyanti, 2006), but the effect is slightly different (Blesbois et al., 2004; Estienne et al., 2008). Omega-3 and omega-6 with higher dose $(6 \%)$ were able to show its effect in improving the sperm quality of quails. The abnormality of sperm increased in almost all treatments, because of the side effect of the semen collection technique, so it caused damage to the spermatozoa. It is recommended that the massage method should be used for the collection of quail sperm. The quality and availability of feed is the major factor behind efficient quail production (Elangovan et al., 2001). Fat contained in omega 3 and omega 6 is a food substance that serves as a precursor of testosterone (Haglund et al., 1998). The highest hormone levels are seen when entering the breeding season (Zanuy et al., 1999).

The results of this study show that omega- 3 and omega- 6 fatty acid doses $0.326 \mathrm{mg} /$ day $/ 100 \mathrm{~g}$ BW can increase testosterone level in blood plasma, but the dose recommended by WHO $(0.163 \mathrm{mg})$ indicates a lower value than the control. Cholesterol with a dose of 20 $\mathrm{mg} /$ day/100 g BW showed higher cholesterol level in blood plasma of male quails than cholesterol with the dose of $40 \mathrm{mg} /$ day/100 g BW. Cholesterol with the dose of WHO recommended (20 mg), and high doses $(40 \mathrm{mg})$ showed higher testosterone levels than control.

The increase of testosterone level in high dose omega-3 treatment (Table 3) were equivalent with a decrease of testosterone level in total cholesterol $(174.1 \mathrm{mg} / \mathrm{dl})$, HDL $(46.3 \mathrm{mg} / \mathrm{dl})$ and LDL (18.44/dl) in blood serum of the male quail, because most cholesterol has been synthesized into the testosterone hormone (Blesbois et al., 2004; Haryati, 2001; Muryanti, 2005). Testosterone hormone is synthesized from cholesterol in Leydig cells and adrenal glands, so it will automatically affect the content of HDL and LDL in the blood serum (O'Donnell et al., 1996; Retterstol et al., 1998). As a result of that, the time analysis of cholesterol level, LDL and HDL are detected to be slightly reduced.

The results of this study showed that the heaviest weight of the testes is caused by the treatment of fatty acids and cholesterol and it will be supported by an increase in the size of uropygium. The weight of the testes weight also increased in the process of spermatogenesis (Grote et al., 2008; Kelso et al., 1997).

In Table 4, the right and the left testicles of the quail treated with fatty acids or cholesterol have ideal size. The testes size indicated the bigger group were treated quail fatty acids and cholesterol (Fitriyah, 2010). This is in accordance with the opinion of Surai et al. (2000), that the addition of many Arasco oil contains omega- 6 is arachidonate $(20: 4 n-6)$ on the chicken was able to improve the content of fatty acids in the testes, especially DHA (22:4n-6) and EPA (20:5n-3). Increase the weight of the testes cause an increase in testes mass, indirectly increasing the number of sperm (Giraudeau et al., 2016). The increase in the size of the testes is positively associated with sperm production.

The heaviest testicular weight in this study was shown by the treatment of fatty acids and cholesterol, that caused by an increase in testosterone level, as shown in Table 4.

The seminiferous tubules in treatment R-0 contain only a few spermatogenic cells (Fig.1, R-0) and the distance between each of the seminiferous tubules is tenuous. The lack of spermatogenic cells is suspected to 
be due to the lack of ICSH level for normal spermatogenesis process so that the germinal cell is impaired because ICSH stimulates the growth of interstitial cells especially Leydig cells (Srivastava and Pande, 2017). Omega fatty acid and cholesterol can increase the diameter of the seminiferous tubules with normal spermatogenic cell circumstances (Fig.1, treatment R-1, R-2, R-3, R-5, and R-6). The polyunsaturated fatty acids (20: $4 \mathrm{n}-6)$ (Surai and Sparks, 2000), (22: 4n-6) (Khatibjoo et al., 2011) (20: 5n-3) (Darin-Bennett et al., 1974) can stimulate the development of spermatogenesis and also will increase the testicular mass and spermatozoa development.

\section{Conclusion}

The administration of $0.326 \mathrm{mg}$ omega- 3 and omega6 fatty acid affected the size of the reproductive organs (testes and uropygium), increased the sperm quality and the testosterone level in the blood.

\section{Acknowledgment}

We are thanks to The Ministry of Research (DIKTI), Technology and Higher Education Indonesia.

\section{Funding Information}

This work was supported by The Ministry of Research (DIKTI), Technology and Higher Education Indonesia with contract no: 65/SP-MP3EI/010/KM/2014.

\section{Author Contributions}

Abyadul Fitriyah and Supriyono: Conception and design of the study.

Supriyono: Acquisition of data.

Supriyono and Isyaturriyadhah: Analysis and interpretation of data.

Abyadul Fitriyah: Drafting the manuscript.

Abyadul Fitriyah and Isyaturriyadhah: Critical revision. All authors have read and approved the manuscript.

\section{Conflict of Interest}

All of the authors confirm that this article is original and no ethical issues are concerned with the present article.

\section{References}

Anonymous, 2014a. Testosterone (Internet). https://en.wikipedia.org/wiki/Testosterone

Anonymous, 2014b. Omega-3 Fatty Acids: An Essential Contribution.

https://www.hsph.harvard.edu/nutritionsource/wwha -should-you-eat/fats-and-cholesterol/types-offat/omega-3-fats/
Anonymous 2014c. Omega-6 fatty acid. (Internet). https://en.wikipedia.org/wiki/Omega-6_fatty_acid

Anonymous, 2014d. Cholesterol (Internet). https://en.wikipedia.org/wiki/Cholesterol

Bhanja, S.K., and S.V.S. Verma, 2001. Potential feeding value of deoiled rice bran by Japanese quails. 2 . Effect on nutrient utilization. Asian Aus. J. Animal Sci., 14: 1144-1148. DOI: 10.5713/ajas.2001.1144

Blesbois, E., V. Douard, M. Germain, P. Boniface, and F. Pellet, 2004. Effects of $n$ three polyunsaturated dietary supplementations on the reproductive capacity of male turkeys. Theriogenology, 61: 537-549. DOI: 10.1016/S0093-691X(03)00207-3

Bobadilla-Mendez, M.F., C.P. Rojas-Granados, E.F. Andrade, P.L. Retes and L.G. Ferreira et al., 2016. Effect of different light sources on reproductive anatomy and physiology of Japanese quail (Coturnix coturnix japonica). Animal Reproduction Sci., 168: 50-56. DOI: 10.1016/j.anireprosci.2016.02.025

Brind, J., N. Borofsky, K. Chervinsky, J.H. Vogelman, and N. Orentreich, 1996. A simple, differential extraction method for the simultaneous direct radioimmunoassay of androgens and androgen glucuronides in human serum. Steroids, 61: 429-432. DOI: 10.1016/0039-128X(96)00063-3

Chelmonska, B., A. Jeryszi, E.L. Ukaszewicz, A. Kowalczyk and I. Malecki, 2008. Semen collection from Japanese quail (Coturnix japonica) using a teaser female. Turki J. Vet. Animal Sci., 32: 19-24.

Chełmońska, B., E. Łukaszewicz, A. Kowalczyk and A. Jerysz, 2006. The effect of DMA level on morphology and fertilizing ability of Japanese quail (Coturnix japonica) spermatozoa. Theriogenology, 65: 451-458.

DOI: $10.1016 / \mathrm{j}$.theriogenology.2005.06.002

Darin-Bennett, A., A. Poulus and I.G. White, 1974. The phospholipids and phospholipid-bound fatty acids of dog and fowl spermatozoa. J. Reproduction Fertility, 41: 471-474.

Dumpala, P.R., H.M. Parker, and C.D. McDaniel, 2006. The sperm quality index from fresh semen predicts chicken semen quality after storage. Int. J. Poultry Sci., 5: 850-855. DOI:10.3923/ijps.2006.850.855

Elangovan, A.V., S.V.S. Verma, V.R.B. Sastry, and S.D. Singh, 2001. Effect of feeding high glucosinolate rapeseed meal to laying Japanese quail. AsianAustralasian J. Animal Sci., 14: 1304-1307. DOI: 10.5713/ajas.2001.1304

Estienne, M.J., A.F. Harper and R.J Crawford, 2008. Dietary supplementation with a source of omega-3 fatty acids increases sperm number and the duration of ejaculation in boars. Theriogenology, 70: 70-76. DOI: 10.1016/j.theriogenology.2008.02.007 
Fitriyah, A., 2010. The utilization of testosterone hormone precursor in the feed on the reproductive performance of the male quails (Coturnix coturnix japonica). Thesis of Animal Science, Gadjah Mada University, Yogyakarta, Indonesia.

Giraudeau, M., A.K. Ziegler and B. Tschirren, 2016. Long-term effect of yolk carotenoid levels on testis size in a precocial bird. Biology Lett., 12: pii: 20160008. DOI: 10.1098/rsbl.2016.0008

Grote, K., L. Niemann, B. Selzsam, I. Chahoud and C. Gericke et al., 2008. Chahoud I. Epoxiconazole causes changes in testicular histology and sperm production in the Japanese quail (Coturnix coturnix japonica). Environ. Toxicology Chemistry, 27: 2368-74. DOI: 10.1897/08-048.1

Haglund, O., R. Wallin, S. Wretling, B. Hultberg and T. Saldeen, 1998. Effects of fish oil alone and combined with long chain (n-6) fatty acids on some coronary risk factors in male subjects. J. Nutrition, 9: 629-635. DOI: 10.1016/S0955-2863(98)00065-5

Haryati, 2001. The effect of the hormone testosterone and oxytocin on the quantity and quality of black chicken kedu sperm. Thesis of Animal Science, Gadjah Mada University, Yogyakarta, Indonesia

Ipek, A., O. Canbolat and A. Karabulut, 2007. The effect of vitamin e and vitamin $\mathrm{c}$ on the performance of Japanese quails (Coturnix Coturnix Japonica) reared under heat stress during growth and egg production period. Asian Aus. J. Animal Sci., 20: 252-256. DOI: 10.5713/ajas.2007.252

Iriyanti, N., 2006. The utilizing of nonsaturated fatty acids and vitamin $\mathrm{E}$ in Rotions on reproduction and production native chicken. Thesis of Animal Science, Gadjah Mada University, Yogyakarta, Indonesia.

Kelso, K.A., S. Cerolini, B.K. Speake, L.G. Cavalchini and R.C. Noble, 1997. Effect of dietary supplementation with á-linoleic acid on the phospholipid fatty acid composition and the quality spermatozoa in the cockerel from 24 to 72 weeks of age. J. Reproduction Fertility, 110: 53-59.

Khatibjoo, A., H. Kermanshahi, R. Alimon, A. Golian and M. Zaghari, 2011. Effect of omega6:omega3 fatty acid ratios on semen quality of Malaysian village roosters. Universiti Putra Malaysia Institutional Repository (UMPIR), Malaysia.

Muryanti, Y., 2005. Testosterone level and sperm quality of mice (Mus musculus 1.) after given Saga (Abrus precatorius L.) sees extract. Thesis of Doctor of Animal Science, Gadjah Mada University, Yogyakarta, Indonesia.
Nalbandov, A.V., 1964. Reproductive Physiology: Comparative Reproductive Physiology of Domestic Animals, Laboratory Animals and Man, 2nd Edn., San Francisco, Calif.: Freeman, c1964. https://trove.nla.gov.au/version/12369793

O'Donnell, L., R.I. McLachlan, N.G. Wreford, D.N de Kretser and D.M. Robertson, 1996. Testosterone withdrawal promotes stage-specific detachment of round spermatids from the rat seminiferous epithelium. J. Biology Reproduction, 55: 895-901. https://www.ncbi.nlm.nih.gov/pubmed/8879506

Retterstol, K., T.B. Haugen, B. Woldseth and B.O. Christophersen, 1998. A comparative study of the metabolism of n-9, n- 6 and n-3 fatty acids in testicular cells from immature rat. Biochimica at Biophysica Acta, 1392: 59-72.

DOI: 10.1016/S0005-2760(98)00021-6

Sorensen, A.M., Jr. 1979. Animal Reproduction, Principles and Practices, 1st Edn., McGraw-Hill Book Company. New York, USA, ISBN-10: 0070596700, pp: 496.

Srivastava, N. and M. Pande, 2017. Protocols in semen biology (Comparing Assays). Springer Nature Singapore Pte Ltd.

Steel, R.G.D. and J.H. Torrie, 1980. Principles and Procedures of Statistics a Biometrical Approach, 2nd Edn., New York McGraw-Hill.

Sudargo, T., I. Astuti, E.N. Sholikhah, R. Amelia and L. Maknunah et al., 2017. The effect of kersen juice on lipid profile of spargue dawley rats: A randomized controlled trial. Asian J. Clinical Nutrition, 9: 97-103.

DOI: $10.3923 /$ ajcn.2017.97.103

Surai, P.F. and N.H. Sparks, 2000. Tissue-specific fatty acid and $\alpha$-tocopherol profiles in male chickens depending on dietary tuna oil and vitamin E provision. Poultry Sci., 79: 1132-1142. DOI: $10.1093 / \mathrm{ps} / 79.8 .1132$.

Surai, P.F., R.C. Noble, N.H. Sparks and B.K. Speake, 2000. Effect of long-term supplementation with arachidonic or docosahexaenoic acids on sperm production in the Broiler chicken. J. Reproduction Fertility, 120: 257-264.

Wathes, D.C., D.E. Robert, Abayasekara and R.J. Aitken, 2007. Polyunsaturated fatty acids in male and female reproduction. Minireview. Biology Reproduction, 77: 190-201. DOI 10.1095/biolreprod.107.060558

Zanuy, S., M. Carrillo, J. Mateos, V. Trudeau and O. Kah, 1999. Effect of sustained administration of testosterone in pre-pubertal sea bass (Dicentrarchus labrax L). Aquaculture, 177: 21-35.

DOI: 10.1016/S0044-8486(99)00066-6 